\title{
A prática docente de professores não licenciados no Ensino Médio Integrado à Educação Profissional e Tecnológica
}

The teaching practice of nonlicensed teachers in High School Integrated to Professional and Technological Education

\author{
COSTA, Marcelo George Nogueira da. Discente do curso de Mestrado Profissional em \\ Educação Profissional e Tecnológica \\ Instituto Federal de Educação Ciência e Tecnologia do Sertão Pernambucano - IF Sertão Campus Salgueiro. \\ Salgueiro - PE - Brasil. / E-mail: marcelo.george@ifsertao-pe.edu.br
}

\section{OLIVEIRA, Francisco Kelsen de. Doutor Ciência da Computação}

Instituto Federal de Educação Ciência e Tecnologia do Sertão Pernambucano- IF Sertão Campus Salgueiro. Salgueiro - PE - Brasil. / E-mail: francisco.oliveira@ifsertao-pe.edu.br

\section{RESUMO}

O interesse por estudos sobre a formação de professores para a Educação Profissional e Tecnológica (EPT) tem aumentado na última década. Parte das publicações, voltadas a essa temática, tem como foco os saberes docentes, as demandas formativas e a constituição da identidade do professor, em especial os bacharéis e tecnólogos, visto que além dos conhecimentos técnicos, específicos de sua formação, os professores precisam apresentar o domínio das questões pedagógicas e didáticas, próprias do trabalho da sala de aula. Dessa forma, este artigo busca identificar quais as principais dificuldades enfrentadas por docentes não licenciados nos cursos de Ensino Médio Integrado (EMI) à EPT, suas demandas formativas e os registros de políticas de formação do quadro docente da EPT a partir de uma revisão sistemática de literatura (RSL). Para isso, utilizou-se o processo de RSL, no qual foram analisados artigos científicos publicados entre 2008 e 2020 com relevância vinculada a esta pesquisa. Os resultados deste estudo apontam para a necessidade de políticas públicas voltadas à instituição e ao estímulo de formações pedagógicas do quadro docente da EPT, principalmente dos profissionais egressos dos cursos de bacharelado e de tecnologias.

Palavras-chave: Educação Profissional e Tecnológica, Ensino Médio Integrado, demandas formativas, professores não-licenciados, políticas de formação docente.

\begin{abstract}
Interest in teacher education for Professional and Technological Education (EPT) has increased in the last decade. Part of the publications, focused on this theme, focuses on teaching knowledge, formative demands and the constitution of the teacher's identity, especially the bachelors and technologists, since in addition to the technical knowledge, specific to their training, teachers need to present the mastery of pedagogical and didactic issues, specific to the work of the classroom. Thus, this article seeks to identify the main difficulties faced by non-graduate teachers in integrated high school (EMI) courses to EPT, their formative demands and the records of EPT education policies based on a systematic literature review (RSL). For this, we used the RSL process, in which scientific articles published between 2008 and 2020 were analyzed with relevance linked to this research. The results of this study point to the need for public policies aimed at the institution and the stimulation of pedagogical training of the EPT teaching staff, especially professionals who graduated from bachelor's and technology courses.
\end{abstract}

Keywords: Professional and Technological Education, Integrated High School, formative demands, non-licensed teachers, teacher training policies. 
COSTA, M. G. N. da.; OLIVEIRA, F. K. de. (2020)

A prática docente de professores não licenciados no Ensino Médio Integrado à Educação Profissional e Tecnológica

\section{Introdução}

O interesse pelos estudos sobre a formação de professores para a Educação Profissional e Tecnológica (EPT) aumentou a partir do ano de 2010 e isso pode ter como razão, segundo Vieira (2018), a criação dos institutos federais (IFs) em 2008, através da Lei $n^{\circ}$ 11.892/2008 (BRASIL, 2008), ampliando assim o número de docentes a atuar nessa modalidade de ensino. Ainda segundo o autor, grande parte dos trabalhos publicados tem como foco os saberes docentes, as demandas formativas e a constituição da identidade do professor, em especial os bacharéis e tecnólogos, visto que além dos conhecimentos técnicos, específicos de sua formação, os professores precisam apresentar o domínio das questões pedagógicas e didáticas, próprias do trabalho da sala de aula.

Diante dessa realidade, houve a necessidade de se refletir sobre os desafios do magistério, tendo em vista, segundo Oliveira e Sales (2015), o grande número de professores não licenciados atuando na EPT e mais especificamente no Ensino Médio Integrado (EMI). Portanto, esse trabalho tem como objetivo identificar quais as principais dificuldades enfrentadas por docentes não licenciados nos cursos de EMI, suas demandas formativas e os registros de políticas de formação do quadro docente da EPT a partir de uma revisão sistemática de literatura (RSL).

A partir da motivação de pesquisa apresentada, foram elaboradas questões a serem respondidas por artigos científicos publicados entre 2008 e 2020. A busca foi realizada no Google Acadêmico e para isso, utilizou-se, como referência metodológica, o processo de RSL de Oliveira e Gomes (2015).

A fim de um maior aprofundamento sobre o tema de estudo, serão abordados, na próxima seção, aspectos teórico-conceituais sobre a EPT, o EMI e a formação docente. Logo após serão expostos os materiais e métodos usados nesta pesquisa, os resultados e discussão e as conclusões.

\section{A Educação Profissional e Tecnológica}

A Educação Profissional e Tecnológica (EPT), no que determina a Lei de Diretrizes e Bases da Educação Nacional (LDB), é uma modalidade de ensino cujos objetivos estão estabelecidos nas dimensões do trabalho, ciência, cultura e tecnologia (BRASIL, 1996). Assim, seu papel é de fundamental importância por oportunizar o acesso ao pensamento crítico, científico e tecnológico, para além das exigências do mercado de trabalho, assumindo um compromisso com a educação pública de qualidade e com a emancipação humana.

Buscando uma formação completa ou integral, politécnica e omnilateral, como apontam Araújo e Frigotto (2015), essa modalidade de ensino se baseia no trabalho como princípio educativo e na pesquisa como princípio pedagógico. Nesse sentido, abre-se espaço para que a construção do conhecimento ocorra de forma autônoma e promova o desenvolvimento de habilidades como trabalhar de forma coletiva, guiada, criativa e crítica. Para Pistrak (2009), essa força criativa é potencializada, precipuamente, através de estratégias de problematização da realidade e dos conteúdos escolares.

Em geral, a EPT incentiva, não só por meio do ensino, mas também mediante projetos integradores pesquisa, inovação ou extensão, transcender as barreiras impostas pela divisão do 
COSTA, M. G. N. da.; OLIVEIRA, F. K. de. (2020)

A prática docente de professores não licenciados no Ensino Médio Integrado à Educação Profissional e Tecnológica

conhecimento em disciplinas, constituindo-se como uma ferramenta imprescindível ao atendimento das demandas formativas de uma sociedade, na qual o conhecimento é produzido e acessado em uma velocidade inédita. Esses objetivos podem ser atendidos, segundo Araújo e Frigotto (2015), principalmente através do EMI, que será abordado na próxima seção.

\section{Ensino Médio Integrado à Educação Profissional e Tecnológica}

O Ensino Médio Integrado à Educação Profissional e Tecnológica apresenta e propõe, através da integração da educação geral à educação profissional, a perspectiva de formação politécnica em que o currículo integrado seja planejado tendo com horizonte a emancipação humana.

Nessa modalidade, o aprendiz deve ser visto como um ser social que traz consigo experiência acumulada, diferentes saberes, aprendizagens e histórias de vida que são potencializadas, em todas as suas dimensões, por práticas educativas integradoras. Assim, esse estudante poderá transformar sua realidade por meio da articulação de seus conhecimentos prévios e dos construídos na vivência escolar e terá capacidade de permanecer aprendendo mesmo após os estudos formais.

Apesar das potencialidades supracitadas do EMI, segundo Almeida, Salem e Silvino (2018, p.3), uma

[...] parcela significativa de alunos que ingressam no ensino médio integrado enfrentam elevada dificuldade de conciliar as várias disciplinas-base com as disciplinas técnicas/específicas das áreas referentes a seu Curso (Administração, Agroindústria, Agropecuária e Informática). 0 ensino profissional e tecnológico exige do aluno, pelo menos de início, esforço redobrado, talvez por vir de realidade diferente do que passa a conviver ao ingressar nesta modalidade de ensino. Isto contribui para o baixo rendimento e, assim, carecem de que a Instituição tenha um olhar diferenciado.

A escola tradicional deve dar espaço para a escola de (re) construção do conhecimento, onde os saberes são o ponto de chegada e o ponto de partida do aluno. Educação, ciência e tecnologia não estão a serviço do que Paulo Freire (1987) chama de "educação bancária", segundo a qual os conhecimentos são depositados no aluno de forma passiva e unilateral, mas de uma aprendizagem significativa, crítica, dinâmica e reflexiva.

Carneiro (2015) aponta que as principais dificuldades de aprendizagem dos discentes, na modalidade de ensino em estudo, são: a falta de tempo para estudar devido à alta carga horária de aulas e a deficiência de conhecimentos prévios, principalmente na área de exatas, lacunas advindas do Ensino Fundamental e a falta de articulação entre os conteúdos ministrados em sala de aula e a realidade social do estudante.

Esse contexto exige uma atuação docente que atenda aos objetivos da EPT e, em especial, do EMI e promova a superação dos desafios de aprendizagem existentes. Isso pode demandar um formação docente específica para essa modalidade de ensino, o que será abordado na próxima seção. 
COSTA, M. G. N. da.; OLIVEIRA, F. K. de. (2020)

A prática docente de professores não licenciados no Ensino Médio Integrado à Educação Profissional e Tecnológica

\section{Formação Docente para a Educação Profissional e Tecnológica}

Ao se falar em prática pedagógica na EPT, surgem, segundo Oliveira (2016), algumas questões como: os saberes necessários à prática docente, as demandas formativas que englobam as especificidades do exercício pedagógico e a criação identitária do professor da EPT, as medidas do Estado voltadas à formação de docentes, primordialmente os não licenciados e os impactos da ausência dessa formação no processo de ensino-aprendizagem.

De acordo com Oliveira e Sales (2015), os conhecimentos docentes que irão reger a prática pedagógica dos professores não licenciados recém-admitidos, costumam ser construídos por meio da experimentação da "melhor forma de ensinar", visto que a maioria deles geralmente não apresenta a vivência do magistério. Ainda segundo os autores, grande parte desses docentes prestam concurso e optam pela carreira docente na Rede Federal de Educação Profissional, Científica e Tecnológica por conta das condições de trabalho, da estrutura predial dos institutos, da remuneração, da possibilidade de progressão e ascensão financeira, não sendo, dessa forma, um dom ou vocação, mas uma escolha.

Dessa forma, esse cenário demanda uma formação para o exercício da docência na EPT, instituída por políticas públicas nacionais, que atenda não só aos fatores de natureza pedagógica, mas aos aspectos específicos dessa modalidade de ensino.

A seguir são apresentados os materiais e métodos utilizados nesta pesquisa.

\section{Material e métodos}

Foi realizada, na presente pesquisa, uma Revisão Sistemática de Literatura (RSL) desenvolvida por meio de um protocolo compreendendo as especificações de busca realizada e do material obtido como resultado, além dos critérios usados na análise dos achados, com o propósito de torná-la auditável em situações de estudos futuros.

Conforme Oliveira e Gomes (2015), a importância da RSL está no fato de se poder selecionar, dentre vários estudos realizados, aqueles que apresentam os principais conceitos, definições e teorias que se relacionam com o assuntos investigados, servindo ainda para identificação de lacunas deixadas e possibilidades de aprimoramento em novas pesquisas.

Este trabalho seguiu o protocolo de revisão sistemática da literatura (RSL) embasado no modelo empregado por Oliveira e Gomes (2015) e Machado e Oliveira (2019), e apresentou três perguntas principais que foram respondidas por meio da leitura de artigos, as quais estão dispostas no 1:

Quadro 1 - Questões da pesquisa com suas respectivas motivações.

\begin{tabular}{|c|c|l|}
\hline ID & \multicolumn{1}{|c|}{ Perguntas } & \multicolumn{1}{c|}{ Motivação } \\
\hline \multirow{3}{*}{ P1 } & Quais os desafios enfrentados por docentes & Identificar os principais desafios que o docente \\
& não licenciados nas turmas dos cursos & não licenciado tem enfrentado nas turmas dos \\
& técnicos de Nível Médio Integrado (EMI) à & cursos técnicos de Nível Médio Integrado à \\
\hline
\end{tabular}


COSTA, M. G. N. da.; OLIVEIRA, F. K. de. (2020)

A prática docente de professores não licenciados no Ensino Médio Integrado à Educação Profissional e Tecnológica

\begin{tabular}{|l|l|l|}
\hline & Educação Profissional e Tecnológica (EPT)? & Educação Profissional e Tecnológica. \\
\hline P2 & $\begin{array}{l}\text { Quais as demandas formativas dos } \\
\text { professores não licenciados na EPT e em } \\
\text { especial no EMI? }\end{array}$ & $\begin{array}{l}\text { Conhecer as possíveis necessidades formativas } \\
\text { dos docentes não licenciados na sua prática } \\
\text { pedagógica na EPT e em especial no EMI. }\end{array}$ \\
\hline P3 & $\begin{array}{l}\text { Quais os registros de políticas de formação } \\
\text { docente propostas para superar os desafios } \\
\text { enfrentados pelos docentes não } \\
\text { licenciados na EPT e em especial no EMI? }\end{array}$ & $\begin{array}{l}\text { Avaliar ambientes e contextos nos quais soluções } \\
\text { pedagógicas, como formações docentes, estão } \\
\text { sendo utilizados, através das publicações } \\
\text { disponíveis. }\end{array}$ \\
\hline
\end{tabular}

Fonte: o autor, adaptado de Oliveira e Gomes (2015) e Machado e Oliveira (2019).

O processo de seleção das fontes levou em consideração artigos científicos publicados no recorte temporal de 2008 a 2020, período a partir do qual foram criados os Institutos Federais (IFs) através da Lei $n^{\circ}$ 11.892/2008. Foram escolhidas palavras -chave, a partir das perguntas do quadro 1 , e foram dispostas junto com suas variações de primeira, segunda e terceira ordem, de acordo com o quadro 2:

Quadro 2 - Termos selecionados para formação das strings de busca

\begin{tabular}{|c|c|c|}
\hline $1^{\mathrm{a}}$ ordem & $2^{\mathrm{a}}$ ordem & $3^{\mathrm{a}}$ ordem \\
\hline $\begin{array}{l}\text { Educação } \\
\text { profissional e } \\
\text { tecnológica; EPT. }\end{array}$ & $\begin{array}{l}\text { Ensino médio } \\
\text { integrado; EMI. }\end{array}$ & $\begin{array}{l}\text { Docente não licenciado, professores não licenciados; } \\
\text { demandas formativas; políticas de formação docente. }\end{array}$ \\
\hline
\end{tabular}

Fonte: o autor, adaptado de Oliveira e Gomes (2015) e Machado e Oliveira (2019).

A partir da determinação das palavras-chave e de sua disposição no quadro 2, foram criadas strings de busca e pesquisadas na plataforma do Google Acadêmico, conforme quadro 3. Essa plataforma foi utilizada neste primeiro momento, pois já indexa os artigos científicos disponível em outras bases.

Quadro 3 - Strings de buscas nas bases escolhidas para a pesquisa

\begin{tabular}{|l|l|}
\hline \multicolumn{1}{|c|}{ ID } & \multicolumn{1}{c|}{ String de busca } \\
\hline S1 & "EPT"+"ensino médio integrado"+ "docente não licenciado" + (ano>=2008) \\
\hline S2 & "EPT"+"EMl"+ "professores não licenciados" + (ano>=2008) \\
\hline S3 & "EPT" +"EMI" + "demandas formativas" + (ano>=2008) \\
\hline S4 & "educação profissional e tecnológica" +"EMI" + "políticas de formação docente" + (ano>=2008) \\
\hline
\end{tabular}

Fonte: o autor, adaptado de Oliveira e Gomes (2015) e Machado e Oliveira (2019).

Com o propósito de filtrar os trabalhos e aprimorar o seu processo de análise, foram estabelecidos critérios de inclusão e exclusão, como pode ser observado no quadro 4: 
COSTA, M. G. N. da.; OLIVEIRA, F. K. de. (2020)

A prática docente de professores não licenciados no Ensino Médio Integrado à Educação Profissional e Tecnológica

Quadro 4 - Critérios de inclusão ou exclusão

\begin{tabular}{|l|c|l|}
\hline Critérios & ID & \\
\hline \multirow{4}{*}{ Inclusão } & I1 & Artigos completos ou resumos expandidos publicados em periódicos científicos \\
\cline { 2 - 3 } & I2 & Publicação de 2008 a 2020 \\
\hline \multirow{4}{*}{ Exclusão } & E1 & $\begin{array}{l}\text { Artigos não relevantes para a pesquisa (excluídos pelo título, resumo e palavras- } \\
\text { chave que não se relacionam aos objetivos desta RSL) }\end{array}$ \\
\cline { 2 - 3 } & E2 & Teses e dissertações \\
\cline { 2 - 3 } & E3 & Artigos não disponíveis para download \\
\cline { 2 - 3 } & E4 & Artigos disponíveis em outros idiomas \\
\cline { 2 - 3 } & E5 & Trabalhos duplicados \\
\hline
\end{tabular}

Fonte: o autor, adaptado de Oliveira e Gomes (2015) e Machado e Oliveira (2019).

Com base nos critérios de inclusão e exclusão, a pesquisa teve como primeira etapa a leitura do título, das palavras-chave, do resumo e das considerações finais dos artigos. Já na segunda etapa, foram lidos, na íntegra, apenas as publicações que apresentavam as principais fundamentações teóricas e resultados exigidos pelos objetivos deste trabalho.

Na próxima seção, serão apresentados os resultados e discutidos os resultados da pesquisa.

\section{Resultados e discussão}

A partir das perguntas propostas neste trabalho, foram lidos os artigos científicos que atenderam aos critérios de inclusão e exclusão, e procuradas suas respectivas respostas. Assim, no quadro 5 , podem ser observadas, de forma detalhada, as etapas de refinamento da pesquisa, com o número de respostas encontradas, bem como as perguntas do quadro 1 , que podem ser respondidas pelos trabalhos selecionados.

Quadro 5: Resultados da RSL

\begin{tabular}{|c|c|c|c|c|}
\hline ID & $1^{\text {a }}$ Etapa & $2^{\text {a }}$ Etapa & Citação & Perguntas do Quadro 1 \\
\hline S1 & 09 & 02 & $\begin{array}{c}\text { Vieira (2018) } \\
\text { Spricigo, Santos e Santos (2018) }\end{array}$ & P2 e P3 \\
& & & 01 & Moura e Oliveira (2018) \\
\hline S2 & 10 & 01 & Menezes (2015) & P1 e P3 \\
\hline S3 & 06 & 01 & Cavalcante e Henrique (2017) & P2 \\
\hline S4 & 13 & P1 \\
\hline
\end{tabular}

Fonte: o autor, adaptado de Oliveira e Gomes (2015) e Machado e Oliveira (2019).

Os trabalhos de Moura e Oliveira (2018) contribuem com algumas respostas à pergunta 1, ao exporem os principais desafios enfrentados pelo docente não licenciado nas turmas de EMI como dificuldades de preparar aulas para transpor o conhecimento para os alunos de forma acessível, 
COSTA, M. G. N. da.; OLIVEIRA, F. K. de. (2020)

A prática docente de professores não licenciados no Ensino Médio Integrado à Educação Profissional e Tecnológica

avaliação de aprendizagem e indisciplina, desmotivação e falta de conhecimentos prévios dos discentes. Cavalcante e Henrique (2017) reiteram essas dificuldades de caráter pedagógico e complementam a análise apontando que não existe ainda uma apropriação epistemológica das concepções de formação integral e integrada por parte desses docentes e isso faz com que, na maioria dos casos, a sua prática pedagógica ocorra de forma desarticulada de outras áreas do conhecimento.

Reforçando o que foi evidenciado pelos outros autores, Spricigo, Santos e Santos (2018) expõem que os conhecimentos específicos e a experiência profissional na área de origem dos professores não licenciados não são suficientes para atender aos diversos desafios do atual ambiente educacional da EPT tais como relacionamento com os alunos, articulação didática e o uso das tecnologias.

Observa-se que as respostas, embasadas nos estudos apresentados, concentram-se em desafios de natureza pedagógica, como os relacionados à dinâmica operacional da prática educativa diária, e na ausência de domínio dos fundamentos norteadores do EMI por parte dos docentes. Abordou-se também sobre uma desmotivação por parte dos discentes no EMI e isso pode abrir espaço para uma investigação mais detalhada sobre esse problema, como por exemplo, quais os fatores que levam o aluno a ficar desmotivado, quais deles querem seguir a carreira profissional proporcionada pela formação do seu curso e se sentem estimulados pelo estudo das disciplinas técnicas ministradas pelos professores não licenciados. Por fim, outra questão que poderia ser analisada é se o envolvimento dos docentes na EPT com turmas com perfis profissionais tão diversos pode constituir um obstáculo ao bom funcionamento dos cursos integrados.

Em relação à pergunta 2, Spricigo, Santos e Santos (2018) trazem, nos seus estudos, que uma das principais demandas do professor não licenciado é a necessidade de orientações para nortear e facilitar suas práticas diárias em sala de aula. Menezes (2015) reforça essa carência docente e aponta a falta de um direcionamento que além de abordar questões como organização do trabalho pedagógico, currículo do ensino médio integrado, processos avaliativos, promova uma formação reflexiva e contínua do docente.

Vieira (2018) demonstra concordância com as elucidações supracitadas e traz outras contribuições no sentido de contemplar aspectos mais específicos das necessidades do docente não licenciado na EPT tais como a compreensão da amplitude e das exigências do processo de ensinoaprendizagem, a construção de estratégias de comunicação e interação com os alunos e investigação e consideração dos seus conhecimentos prévios e da sua realidade.

As análises, realizadas pelos trabalhos que serviram de aporte para responder à pergunta 2 , apontaram as lacunas de formação docente para exercício na EPT tendo como cerne questões práticas de direcionamento pedagógico e convergiram para a necessidade de apropriação, por parte desses professores, de aspectos dessa modalidade de ensino. Tendo como foco o EMI, alguns temas foram propostos como objeto de estudo em momentos formativos, dentre eles: articulação da educação básica com a educação profissional, currículo integrado, itinerários formativos, politecnia, omnilateralidade, ciência, cultura, tecnologia, trabalho como princípio educativo e pesquisa como princípio pedagógico.

Os trabalhos selecionados para responder à segunda pergunta do quadro 1, não abordaram, 
COSTA, M. G. N. da.; OLIVEIRA, F. K. de. (2020)

A prática docente de professores não licenciados no Ensino Médio Integrado à Educação Profissional e Tecnológica

no entanto, sobre a viabilidade de ferramentas institucionais, presentes no EMI, como o conselho de classe, para o levantamento e o diagnóstico de demandas formativas. Assim, como não só o estudo das lacunas formativas é importante, mas também da criação de espaços e momentos necessários para identificá-las, há uma demanda de mais estudos futuros sobre o tema, tendo como escopo o EMI à EPT.

A pergunta 3, por sua vez, pode ser respondida pelos trabalhos de Vieira (2018) que registram que há pouca ocorrência de relatos de experiências de curso de formação para docentes na e para a EPT, já que, segundo o autor, a maioria dos estudos aponta para a oferta de apenas de cursos de pósgraduação (especialização), cursos especiais de formação pedagógica e até cursos emergenciais. Sua pesquisa defende a necessidade de políticas públicas de caráter nacional para formação docentes e a implementação de cursos de licenciatura voltados aos docentes não licenciados para que tenham a mesma base formativa pedagógica que os professores licenciados, além do domínio de aspectos específicos como EMI, ao trabalho e à educação profissional.

Ao corroborar com os registros supracitados, Moura e Oliveira (2018) apontam os casos de docentes não licenciados, mesmo mestres e doutores, que, após o ingresso na EPT, recorrem a cursos de licenciatura em pedagogia ou cursos de complementação pedagógica. Isso demonstra que há, no âmbito da EPT, uma preocupação com o aprimoramento da prática educativa por uma parcela desses professores. Segundo os autores, essa iniciativa pode ajudar esses profissionais a lidar melhor com os desafios da sala de aula de forma sistematizada, visto que grande parte deles leciona testando metodologias diversas, através da técnica da tentativa e erro, buscando a melhor forma de socializar os conteúdos escolares com seus alunos.

Os estudos de Vieira (2018) e Moura e Oliveira (2018) reforçam a criação de uma identidade do professor da EPT, visto que eles são oriundos dos mais diversos contextos de formação acadêmica e/ou de exercício profissional, além de terem entrado na carreira docente motivados por diversos interesses, dentre os quais estão as condições de trabalho, a oportunidade de crescimento profissional, a estrutura dos IFS, o salário e plano de carreira. Essa modalidade de ensino, segundo eles, vem sofrendo um processo de expansão e possui especificidades complexidades e finalidades que exigem programas diferenciados de formação pedagógica que ocorram de forma perene e sistemática. Por fim, apontam que programas de acolhimentos aos docentes têm sido implementados por alguns IFs como uma forma de promoverem a imersão na sua cultura organizacional e profissional e relatam a importância desse processo até mesmo para o professor licenciado, uma vez que seu processo formativo não the proporcionou a vivência da e na EPT.

Os artigos analisados nesta pesquisa, através da RSL, deram o suporte necessário para responder às três perguntas propostas no quadro 1. Esse trabalhos contribuíram também para uma análise mais aprofundada sobre o tema em estudo e trouxeram algumas nuances da EPT e do EMI necessárias para o entendimento do trabalho do docente da carreira EBTT e, em especial, do não licenciado.

\section{Considerações finais}


COSTA, M. G. N. da.; OLIVEIRA, F. K. de. (2020)

A prática docente de professores não licenciados no Ensino Médio Integrado à Educação Profissional e Tecnológica

Pode-se observar, através dos estudos apontados nesta pesquisa, os desafios enfrentados por docentes não licenciados nas turmas dos cursos de EMI, as demandas formativas desses professores e a necessidade da implementação de políticas públicas voltadas a instituição e o estímulo de formações pedagógicas do quadro docente da EPT, principalmente dos profissionais egressos dos cursos de bacharelado e de tecnologias. Dessa forma, conclui-se que os objetivos deste trabalho foram atingidos.

Algumas das lacunas deixadas nesta pesquisa poderão motivar o desenvolvimento de trabalhos futuros sobre o tema, incluindo novas bases de dados, outros idiomas, como inglês e espanhol, além de outros gêneros acadêmicos como teses, dissertações e monografias.

Por fim, apesar dos desafios e demandas formativas supracitadas serem comuns na Rede Federal de Educação Profissional, Científica e Tecnológica, ainda há uma escassez de pesquisas acadêmicas sobre a formação de professores para a EPT e mais especificamente quando os sujeitos são os docentes não licenciados e o plano de fundo é o EMI e isso indica uma demanda para novas investigações sobre esse tema.

\section{Referências}

ALMEIDA, Eliane; SALEM, Gabriel Simões; SILVINO, João da Silva. Potencialidades do reforço escolar assistido a alunos do Ensino Médio Integrado à Educação Profissional no IFMA Campus Caxias. In: V CONEDU: Congresso Nacional de Educação, 5., 2018, Olinda. Anais [...] Campina Grande: Editora Realize, 2018. p.1-8. Disponível em: https://editorarealize.com.br/artigo/visualizar/48651. Acesso em 14 set. 2020

ARAUJO, Ronaldo Marcos de Lima; FRIGOTTO, Gaudêncio. Práticas pedagógicas e ensino integrado. Revista Educação em Questão, v. 52, n. 38, p. 61-80, 2015. Disponível em: <https://periodicos.ufrn.br/educacaoemquestao/article/viewFile/7956/5723>. Acesso em 20 ago. 2020.

BRASIL. Lei $n^{\circ}$ 11.892, de 29 de dezembro de 2008. Institui a Rede Federal de Educação Profissional, Científica e Tecnológica, cria os Institutos Federais de Educação, Ciência e Tecnologia, e dá outras providências. Disponível em: http://www.planalto.gov.br/ccivil_03/_ato20072010/2008/lei/l11892.htm. Acesso em 05 set. 2020.

BRASIL. Lei $\mathrm{n}^{\circ}$ 9.394, de 20 de dezembro de 1996. Estabelece as diretrizes e bases da educação nacional. Brasília, DF, 1996. Disponível em: http://www.planalto.gov.br/ccivil_03/leis/19394.htm. Acesso em 12 ago. 2020.

CARNEIRO, I. M. S. P.; PORTES, L.F. . O processo de ensino e aprendizagem nos cursos técnicos do Instituto Federal do Ceará, campus de Maracanaú. In: José Albio Moreira de Sales; Isabel Maria Sabino de Farias; Maria Socorro Lucena Lima; Maria Marina Dias Cavalcante. (Org.). Didática e a prática de ensino na relação com a sociedade. 1ed.Fortaleza: Ed UECE, 2015, v. 3, p. 3016-. 
COSTA, M. G. N. da.; OLIVEIRA, F. K. de. (2020)

A prática docente de professores não licenciados no Ensino Médio Integrado à Educação Profissional e Tecnológica

FERREIRA, Ilane Cavalcante; HENRIQUE, Ana Lúcia Sarmento. A Experiência da Pesquisa na Formação Docente: Unindo Teoria à Prática. Revista Brasileira de Educação Profissional e Tecnológica, V. 1, P. 16-35, 2017. Disponível em: http://www2.ifrn.edu.br/ojs/index.php/RBEPT/article/view/5730/pdf. Acesso em 15 ago. 2020.

FREIRE, Paulo. Pedagogia do oprimido. Rio de Janeiro: Paz e Terra, 1987.

MACHADO, Y. F.; OLIVEIRA, F. K.. Orientação Profissional, Gamificação e Educação Profissional e Tecnológica: Uma Revisão Sistemática de Literatura. Educação Profissional e Tecnológica em Revista, v. v. 3, p. 108-126, 2019. Disponível em: https://ojs.ifes.edu.br/index.php/ept/article/view/380/341 Acesso em: 12 set. 2020.

MENEZES, Graziela Ninck D.. O Trabalho Docente na Educação Profissional Técnica. 2015. (Apresentação de Trabalho/Comunicação). Disponível em: http://37reuniao.anped.org.br/wpcontent/uploads/2015/02/Trabalho-GT09-3617.pdf. Acesso em 12 set. 2020.

OLIVEIRA, Francisco Kelsen; GOMES, Alex Sandro. Uma revisão sistemática da literatura sobre ferramentas de autoria de IMS-LD. Anais do XXVI Simpósio Brasileiro de Informática na Educação (SBIE 2015), CBIE-LACLO 2015. Disponível em: 10.5753/cbie.sbie.2015.376. Acesso em 18 de set 2020.

OLIVEIRA, R. S e SALES, M. A. O. Professor leigo: releituras sobre os saberes profissionais na Educação Profissional e Tecnológica. In: Colóquio Docência e Diversidade na Educação Básica: políticas práticas e formação, II, 2015. Anais... Salvador: EDUNEB, v. 1. p. 187-200, 2015a.

OLIVEIRA, A. S. A formação do professor para a educação profissional: mapeando a produção bibliográfica. 2016. 136 f. Dissertação (Mestrado em Educação) - Universidade Estadual do Sudoeste da Bahia, Programa de Pós-graduação em Educação, Vitória da Conquista, 2016. Disponível em: http://www2.uesb.br/ppg/ppged/wp-content/uploads/2016/09/Anely-S-Oliveira.pdf. Acesso em: 18 de set 2020.

OLIVEIRA, W. L.; MOURA, R.. Formação Inicial e Trabalho Docente no Instituto Federal de São Paulo. Revista Eixo, 2018. Disponível em: http://revistaeixo.ifb.edu.br/index.php/RevistaEixo/article/view/506/370. Acesso em: 05 de set 2020.

PISTRAK (Org.). A escola-comuna. São Paulo: Expressão Popular, 2009.

SPRICIGO, Fabrício; DOS SANTOS, Thisciana Fialho; DOS SANTOS, Marisilvia. Grupo de Estudos 
COSTA, M. G. N. da.; OLIVEIRA, F. K. de. (2020)

A prática docente de professores não licenciados no Ensino Médio Integrado à Educação Profissional e Tecnológica

Pedagógicos Como Proposta de Desenvolvimento Profissional: Contribuições ao Trabalho Docente na Educação Profissional, Científica e Tecnológica. Revista Tempos e Espaços Em Educação (Online), v. 11, p. 83-96, 2018. Disponível em: https://seer.ufs.br/index.php/revtee/article/view/6720/pdf. Acesso em: 15 set. 2020.

VIEIRA, M. M. M.. Formação de professores da educação profissional: análise de produções acadêmicas. HOLOS (NATAL. ONLINE), v. 2, p. 243-258, 2018. Disponível em: http://www2.ifrn.edu.br/ojs/index.php/HOLOS/article/view/3160/pdf. Acesso em: 26 set. 2020. 